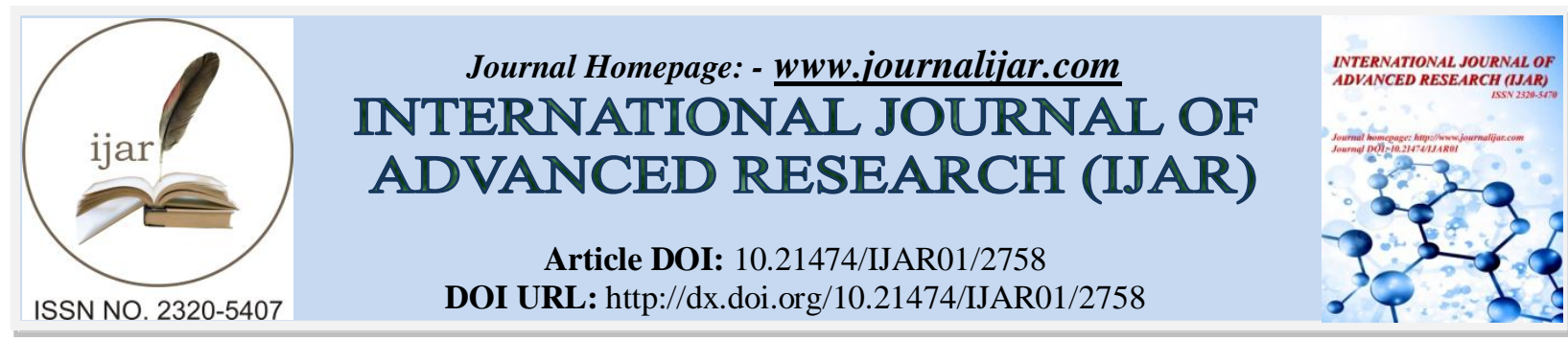

RESEARCH ARTICLE

\title{
ELIMINATION CONTORTION OR MISS SHAPING EFFECT IN VERTICAL POLE (MAST) OF 5OT LEVEL LUFING CRANE.
}

\author{
Mohammed Aadil $\mathbf{U}^{1}$, Urvish V. Brahmbhatt ${ }^{1}$ and Divyeshkumar P. Dave ${ }^{2}$. \\ 1. Dr. Jivraj Mehta Institute of Technology, Mogar, Anand, Gujarat, India. \\ 2. Parul Institute of Technology, Department of Mechanical Engineering, Parul University, P.O.Limda, \\ Ta.Waghodia -391760, Vadodara, Gujarat(India).
}

\section{Manuscript Info ........................... \\ Manuscript History \\ Received: 15 November 2016 \\ Final Accepted: 17 December 2016 \\ Published: January 2017}

Key words:-

Luffing crane, dockyard, deformation, fixture, mast

\begin{abstract}
A level luffing crane is very useful crane in industry as well as at dockyard, ports etc. A level luffing crane consists of a vertical mast which is a very important and supporting structure of crane. Due to various loads of crane like dead load of a crane, load carried by crane etc. the cross section of mast is subjected to deformation. Also changes in diameter occur due to welding is called distortion. The objective of this work is to reduce deformation and distortion of vertical mast. A distortion can be reduced by developing fixture and deformation can be reduced by designing and analysing of mast on software.
\end{abstract}

Copy Right, IJAR, 2016,. All rights reserved.

\section{Introduction:-}

The deformation occurs due to force applied on vertical mast of crane as it is constructed by 13 segments and a flange of $100 \mathrm{~mm}$ height provided on mast.[1] It consists of mild steel(MS) E250J2 material of thickness $22 \mathrm{~mm}$. Outer diameter of vertical mast is $3520 \mathrm{~mm}$ and Inner diameter is $3476 \mathrm{~mm}$ with a length of $14460 \mathrm{~mm}$. As a dead load of 150 tone applied on mast it get deformed by maximum deformation occur on mast.

In material science, deformation refers to any changes in the shape or size of an object due to-

- $\quad$ an applied force

- a change in temperature

Depending of the type of material, size and geometry of the object and the force applied on various types of deformation may result. The different types of deformation occur are as follows. [2]

- Elastic deformation.

- Plastic deformation

Effects of deformation:-

Due to deformation the mast bend littlie downward and can damage the crane. As it is a main support on which crane rotates and carry load can cause damage in machinery and girder. It makes material uncap able to withstand[3].

\section{Distortion:-}

Distortion in weld results from the expansion and contraction of the weld metal and adjacent base metal during the heating and cooling cycle of welding process. There are various types of distortion and dimensional change including 
longitudinal, transverse, angular twisting, buckling and bowing. Two or more types of distortion may occur at the same time[4]. In a weld joint, expansion and contraction forces act on the weld metal and on base metal. As the weld metal solidifies and fuses with the base metal, it is in maximum expanded form. On cooling it attempts to contract to the volume it would normally occupy at a lower temperature but it is restrained from doing so. Because of this stress developed between the weld and adjacent base metal[5]. Major effect of distortion are strength of weld joint has been reduced and strength of vertical mast reduces.

In the present study,

\section{Methodology:-}

Firstly, for reducing weld distortion, welding was observed and measured the diameter of segments by using mechanical measuring tape. Afterward more knowledge about distortion was taken. The original diameter of vertical mast is $\varnothing 3520 \mathrm{~mm}$ outside and inside diameter is $\varnothing 3476 \mathrm{~mm}$. When distortion occurs in first two segments, the diameter was $3526 \mathrm{~mm}$ and by joining $3^{\text {rd }}$ segment, it becomes $3531 \mathrm{~mm}$. But as per company requirement it should be maximum $\pm 5 \%$, which is acceptable.

\section{Heat treatment method:-}

When heat treatment method is used, the result is achieved $3533 \mathrm{~mm}$ which is $13 \%$ more than original diameter. But heat treatment method is time consumable method and very costly [6].

\section{Re-rolling method:-}

But this method is not possible because it require huge machine for rolling and this also increases the industry cost so, it is not possible to apply [7].

\section{By using fixture:-}

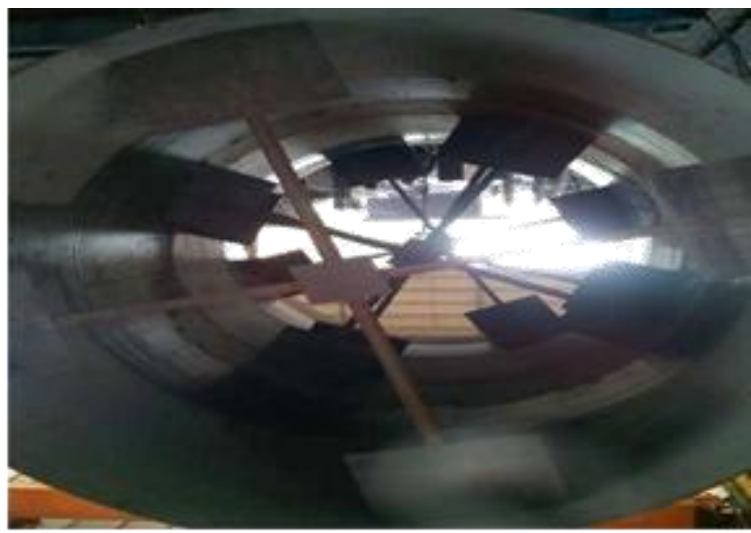

Fig.1. Implementation of Fixture

It is also made by mild steel material with a diameter of $3476 \mathrm{~mm}$ which is internal diameter of vertical mast. The four plate used is of $750 \mathrm{~mm}$ length, $10 \mathrm{~mm}$ thickness and long rod is attached which is welded to four plate, It holds the whole fixture tightly[8].

For reducing deformation of vertical mast, collected necessary data of mast, design it on CRE-O software and analyze it on ANSYS software[9]. So first a mast thickness of $22 \mathrm{~mm}$ and making 13 segments of different height were taken and apply a load of 150 Tone applied and result was found as follows.

The deformation was found $25.478 \mathrm{~mm}$ maximum on top of the mast which is high and as per company requirement it has to be reduced up to $10 \mathrm{~mm}$ at least. After getting the above result it was decided to increase the thickness of mast but overall thickness of mast will increase the cost so, finally just increased the thickness of upper two segments and one bottom segment on which deformation was high. 

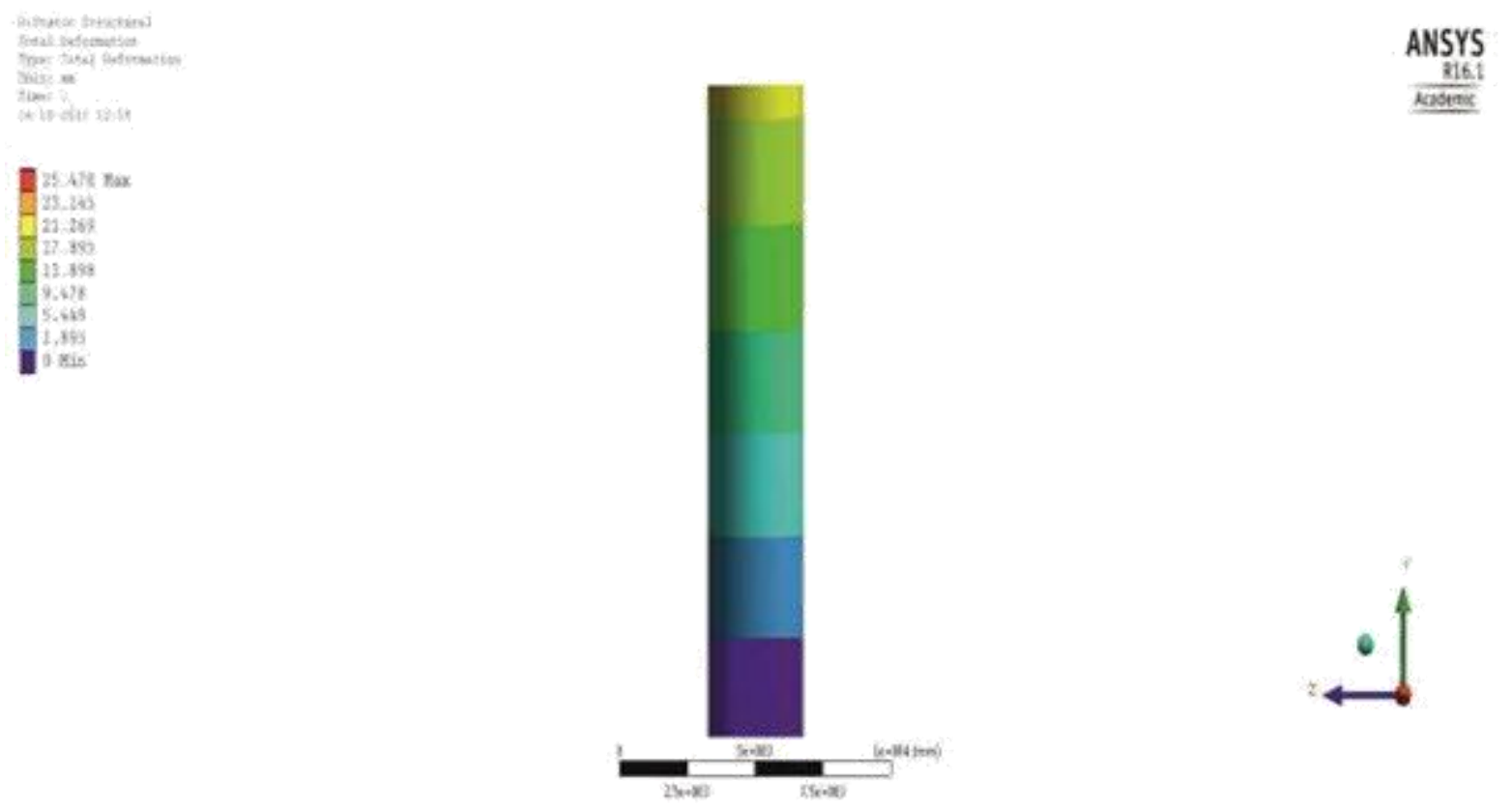

Fig: 2. Design and Analysis of vertical mast for Reduction of deformation

Increasing the thickness of upper two segments and bottom segment thickness from $22 \mathrm{~mm}$ to $26 \mathrm{~mm}$ as per standard given by ASME for material and again analysis is done, results are found as follows. Finally found the better achievement of problem as listed in table1. Deformation of mast reduced up to $7.146 \mathrm{~mm}$ max which is acceptable by company.

Table: 1

\begin{tabular}{|l|l|l|l|}
\hline Load(Tonnes) & Segments & Thickness(mm) & $\begin{array}{l}\text { Maximum } \\
\text { Deformation(mm) }\end{array}$ \\
\hline 150 & 1 to 13 & 22 & 25.478 \\
\hline 150 & $\begin{array}{l}\text { 1st ,2nd and } \\
13 \text { th }\end{array}$ & 26 & 7.146 \\
\hline
\end{tabular}

\section{Result and Discussion:-}

When this fixture is welded and attached to one segment it reduced the segment distortion up to $\pm 5 \%$ which is acceptable in mast. So the distortion reduced and the diameter which was $\varnothing 3534 \mathrm{~mm}$ reduced up to $\varnothing 3523$ which was just 3\% more than its original diameter which is accepted. Same process was done in all 13 segments by applying 1 or 2 fixtures as per requirement and finally the distortion was reduced.

Table 2:

\begin{tabular}{|c|c|c|c|}
\hline \multirow{2}{*}{ Segments } & \multicolumn{2}{|c|}{ Maximum Dia. of Mast(mm) } \\
\cline { 3 - 4 } & & Before weld & After weld \\
\hline Without Fixture & 1 and 2 & 3520 & 3532 \\
\hline With Fixture & 1 and 2 & 3520 & 3523 \\
\hline
\end{tabular}

\section{Conclusion:-}

With the new design for vertical mast by increasing thickness of top two segments and bottom segment, where maximum deformation occurs, for the same analysis was carried out. As a result of deformation, it was reduced to $7.146 \mathrm{~mm}$ maximum. With this the objective of the work was achieved.The problem of distortion is minimized with the use of fixture. After designing of fixture, fixture was implemented in two segments of vertical mast and check the maximum diameter after welding has been completed. The max diameter before weld and after weld was compared for two cases as mentioned in table no. 2 


\section{References:-}

1. D. Suverkrop, "Level luffing crane," Google Patents, 1975.

2. K. Hutter, Theoretical glaciology: material science of ice and the mechanics of glaciers and ice sheets: Springer, 1983.

3. F. Ju, Y. Choo, and F. Cui, "Dynamic response of tower crane induced by the pendulum motion of the payload," International Journal of Solids and Structures, vol. 43, no. 2, pp. 376-389, 2006.

4. Y. Pan, C. Liang, and L. Liu, "The Modeling of Main Hoist Mechanism of Quay Container Crane." pp. 377381.

5. D. Juergens, "Crane control means employing load sensing devices," Google Patents, 1988.

6. S. Allin Sr George, "Lattice boom construction," Google Patents, 1967.

7. A. Nayfeh, Z. Masoud, and N. Nayfeh, "A smart sway controller for cranes from theory to laboratory to industry," Vibration problems ICoVP, pp. 14-29, 2011.

8. K. M. Gyomrey, "Endless chain drive for telescopic jib sections," Google Patents, 1982.

9. V. C. ARVINDKUMAR, " design and analysis of beam for deformation of floor mounted jib crane," atmiya institute of technology and science, 2015. 